\title{
Pragmatic Failure in Cross-cultural Communication of Chinese Students: An Investigation in a Guangxi Normal University
}

\section{Xiaoyao Yue ${ }^{1 *}$, Qian Ding ${ }^{2}$, Yongjun Feng ${ }^{3}$}

${ }^{1}$ Graduate School of Education, Assumption University, 592/3 Ramkhamheang 24, Bangkok 10240 Thailand

${ }^{2}$ School of Foreign Language, Nanning Normal University, No. 3 Hexing Road, Qingxiu Strict, Nanning Province, Guangxi, 530299 China

${ }^{3}$ School of Education, Tangshan Normal University, No.41 North Road of College, District of Lubei, Tangshan City, Hebei Province, 063015 China

*Corresponding author: Xiaoyao Yue

\section{Abstract}

Based on the cross-cultural communicative method and pragmatical method, the author tries to investigate the types of pragmatic failure and the potential causes by test and interview, aiming to find out the problems and give some suggestions to arouse students' pragmatic awareness, to avoid unnecessary pragmatic failures and to improve their pragmatic competence. Through the survey, the author finds that pragmatic failure usually appears in pragmalinguistic failure and sociopragmatic aspects; the teachers have a good knowledge of pragmatic failure and the situation of pragmatic failure among students; negative language transfer, the difference of culture and values between China and western countries are the core causes of pragmatic failure. There are 100 students and four teachers who participate in the investigation. They are the subjects of the research. The students are sophomore and juniors in English major who are randomly chosen from the School of Foreign Languages in a Guangxi Normal University. In addition, the teachers are those who teach the students of English major in a Guangxi Normal University.

Keywords: Cross-cultural competence; Pragmatic failure; Pragmatic competence; Students of English major; Guangxi Normal University.

Copyright @ 2020: This is an open-access article distributed under the terms of the Creative Commons Attribution license which permits unrestricted use, distribution, and reproduction in any medium for non-commercial use (NonCommercial, or CC-BY-NC) provided the original author and source are credited.

\section{INTRODUCTION}

\section{Research Background}

Nowadays, with the development of economy and technology at a high speed, the world that we live become smaller, and the communication between nations is increasingly frequent. China, as one of the developing countries with the fastest development, has more frequent communication with other countries. For example, the G20 held in Hangzhou, the Zhuhai Airshow, and the China-ASEAN Expo held in Guangxi etc. It is a globalization trend that requires a higher standard for the proper use of English in cross-cultural communication activities, especially for the students of English major because they will be the important part of cross-cultural communication in the future.

As we know, the linguistic competence of the students of English major has mostly improved, with higher proficiency in English grammar, good command of vocabulary, but they often have some unsatisfied experience in cross-cultural communication. It is familiar that the students of English major get high scores in the test but still find it hard to make them understood or get across others' meanings when communicating with people from other countries. It is a strange phenomenon that stimulates the author's interest and encourages the author to do an investigation.

According to Jenny Thomas, a British linguist, the situation that learners of a second language cannot successfully make their intended meaning understood by native speakers or fail to understand the intended meaning of native speakers is called pragmatic failure. She pointed in her article [1] that if speakers fail to achieve certain expected purpose in saying something, pragmatic failure will occur. The failure in crosscultural communication is mostly caused by pragmatic failure instead of vocabulary, grammar, or pronunciation. However, in today's English teaching in universities, more emphasis is put on words, phrases, and grammar teaching, so students get good marks in the test but still poor in cross-cultural communication. Therefore, in this research, the author tries to find out the causes of the frequent appearance of pragmatic failure, and give some suggestions to improve students' pragmatic competence in cross-cultural communication. 


\section{Purpose and Significance}

In this research, an investigation is carried out to find out the current situation of pragmatic failure among the students of English major. Through a design of the test and the analysis of the research result, the author will figure out the possible causes of the appearance of pragmatic failure and put forward some effective suggestions to solve the problem.

Up to the present, many researchers contribute a lot to study on this filed, and pragmatic failure has been emphasized. However, researches on the students of English major are rare. It worth noting that concentrates too much on the theoretical achievements of scholars but ignore the investigation into the current situation.

Therefore, it is necessary to make a general investigation in pragmatic failure among the students of English major, which will have not only theoretical but also practical significance. According to the related researches on pragmatic failure, this Survey will focus on the phenomenon of pragmatic failure in crosscultural communication among the students of English major. Based on the previous theories, the author tries to find out what kind of pragmatic failure that the students of English major are prone to invite in crosscultural communication and the causes for students' pragmatic failures in teaching-related and learningrelated factors. Through the analysis of pragmatic failure and the result of the research, some flexible suggestions on how to develop students' pragmatic competence.

\section{LITERATURE REVIEW \\ Cross-cultural Communication Competence}

Since cross-cultural communication competence has a close relationship with cross-cultural pragmatic failure, according to Thomas [1], it is worthwhile to deal with cross-cultural communication competence. At the same time, cross-cultural communication competence is the key to assure successful cross-cultural communication, which is closely connected with the concepts of cross-cultural communication and communicative knowledge.

\section{Cross-cultural Communication}

With the progress of transportation and the development of communicative means, the communication between people from different countries, different races become more frequent, which makes cross-communication an outstanding characteristic of the times. According to Harms [2], cross-cultural communication is the process that people from different cultural backgrounds use the same language to communicate in some specific situations.

\section{Communicative Competence}

The sociolinguist Hymes [3] considered that apart from linguistic competence, the speaker has another rule system, which is "communicative competence." He further claimed that Communicative competence refers to "he or she acquires competence as to when to speak, when not, and as to what to talk about with whom, when, where and manner."

\section{Pragmatic Competence}

Pragmatic competence is one of the most important terms and notions proposed after linguistic competence and communicative competence, which has a rapidly growing in pragmatics. According to Thomas [1], pragmatic competence is the ability to use language effectively in order to achieve a specific purpose and to understand the language in context. As for the students of English major, it is necessary to improve their pragmatic competence to assure effective communication with foreign speakers.

Pragmatics, as an independent discipline of linguistics, appeared in the 1970 s with the publication of the Journal of Pragmatics in 1977. Pragmatic is concerned in the following four areas: speaking meaning; contextual meaning; how more gets than said; the expression of relative distance. According to Thomas [4], Pragmatics is the study of meaning in interaction. Therefore, in order to get the real meaning of the speaker, it is important for the students of English major to have good pragmatic knowledge when they are communicating with foreign speakers.

\section{Pragmatic Failure}

Kasper [5] thought it is common that the speakers fail to get the real meaning of each other when they are having a conversation. Recognizing the knowledge of pragmatic failure will provide some help for the students of English major to avoid some unnecessary mistakes.

\section{Definition of Pragmatic Failure}

In the early 80 's the terms "pragmatic failure" was put forward by British linguist Thomas [4]. She claims that pragmatic failure is the inability to understand what is meant by what is said.

\section{Classification of Pragmatic Failure}

Thomas divided pragmatic failure into two parts, which are pragmalinguistic failure and sociopragmatic failure. It is a general distinction that almost covers every sort of pragmatic failure. Pragmalinguistic failure appears "when the pragmatic force mapped by a speaker onto a given utterance is systematically different from the frequently assigned to it by a native speaker of the target language, or when speech act strategies are inappropriately transferred from L1 to L2" [1]. As for the sociopragmatic failure, unlike pragmatic failure, is closely related to cultures. It 
involves lacking awareness of the conversation and the socio-cultural norms of the target language.

\section{Related Research to Pragmatic Failure}

Huang [6] first suggested "pragmatic error" in his article Pragmatics and Pragmatic Error. He made a qualitative analysis and discussed different meanings of speech acts in different cultural backgrounds. He also pointed out that the proper usage of language in different contexts and backgrounds is as important as grammar, vocabulary, and phonetic knowledge. In consequence, in this research, the author believes that the pragmatic content of speech acts should be involved in the process of language teaching. From that time, the research on pragmatic failure has been increasing progressively. Some effective measures to reduce pragmatic failure have been raised by many scholars through their research on pragmatic failure.

He and Yan [7] investigated pragmatic failure by a quantitative approach. They analyzed the pragmatic differences of cross-cultural communication in both pragmatic and socio-pragmatic aspects based on the theoretical framework of Thomas [4]. The research drew a conclusion that the shortage of linguisticpragmatics knowledge and socio-pragmatic knowledge are the main causes of pragmatic failure for Chinese English learners. Hence, they recommended that knowledge of cross-cultural pragmatic should be covered in language teaching in some way or another. They made a contribution to the analysis of Chinese students' pragmatic failure, and the test they used has been a model in today's pragmatic failure research.

The research of pragmatic failure mentioned above is principally studied from the perspective of pure pragmatics. Wang [8] expanded pragmatic research into the view of cross-cultural, explained the causes and measures of reducing pragmatic failure. Jia [9] put forward that it is cultural differences caused the differences in the aspects of behaviors, greeting, and social values. As Ge [10] notes, background of different culture is the main reason for the improper interaction between speakers and listeners. According to Dai [11] and Zhang [11], one of the primary causes of pragmatic failure is culture transfer.

In language teaching, $\mathrm{Lu} \mathrm{[20]} \mathrm{put} \mathrm{forward} \mathrm{that}$ the change in Chinese language principle has usually been forgotten by us, which causes the native language transfer. Hence, mother tongue transfer, especially negative transfer, is a primary reason in causing pragmatic failure. Han and Yao [13] made an investigation of pragmatic competence among foreignrelated major students and found out that negative transfer of mother tongue is the main reason causing pragmatic failure. Zhu and Zhou [14] pointed out in their research that not only school, teachers but also students need to make efforts together to build a learning atmosphere which benefits for improving the communicative competence of the students of English major.

Through the literature review, it is clear that many scholars have explored the issue of pragmatic failure in cross-cultural communication practically and theoretically. First, the research range has shifted to the socio-cultural perspective from a pure grammatical and lexical perspective. Second, the theoretical framework of pragmatic failure, including definition, sources, and classification with qualitative and quantitative approaches, has been made. However, the researches on pragmatic failure made by the students of English major are rare, and few researchers analyze the causes from the perspective of both students and teachers. Therefore, based on the theories presented by Thomas [4] and the research at home, this thesis will analysis the potential causes of pragmatic failure from the perspective of both teachers and students hoping that this research could help students avoid some unnecessary pragmatic failures in Cross-cultural communication, and find out feasible measures for improving pragmatic competence and Cross-cultural communicative competence.

\section{RESEARCH DESIGN \\ Research Questions}

This research is determined to investigate the pragmatic failures of English students in cross-cultural communication with the following objectives.

- What types of pragmatic failures do the students of English major commit in cross-cultural communication?

- What are the causes of pragmatic failure made by the students of English major?

\section{Sampling Method: Convenient Sampling}

There are 100 students and four teachers who participate in the investigation. They are the subjects of the research. The students are sophomore and juniors in English major who are randomly chosen from the School of Foreign Languages in a Guangxi Normal University. In addition, the teachers are those who teach the students of English major in a Guangxi Normal University.

\section{Research Instruments: Test}

The test that the author uses in this research consists of two parts, which are to examine the subjects' pragmatic failure in cross-cultural verbal communication and in cross-cultural non-verbal communication. In the first part, there are 20 items that describe a verbal behavior with the italic part. In these 20 items, ten are in the pragmaliguistic domain, another ten are in the socio-pragmatic domain. Additionally, the test is designed in the form of multiple choices. Therefore, the subjects should distinguish whether the italic part is appropriate or not. In the second part, it is designed to examine the subjects' failure in crosscultural non-verbal communication, which contains 
non-verbal behaviors and social-cultural knowledge. The test is designed by taking Wang [8] social-cultural test as a reference. Based on the reference, the author made some changes in order to make it more understandable to the subjects.

Table-3.1: Number of test and Rate of validity

\begin{tabular}{|c|c|c|c|c|}
\hline $\begin{array}{l}\text { Number of } \\
\text { distribution }\end{array}$ & $\begin{array}{l}\text { Number of } \\
\text { collection }\end{array}$ & $\begin{array}{c}\text { Valid } \\
\text { number }\end{array}$ & $\begin{array}{l}\text { Invalid } \\
\text { number }\end{array}$ & $\begin{array}{l}\text { Rate of } \\
\text { validity }\end{array}$ \\
\hline 100 & 93 & 93 & 7 & $93 \%$ \\
\hline
\end{tabular}

From the valid test that the author collects, the types of pragmatic failure of the students of English major can be found.

\section{Research Procedures}

The procedures of the investigation were arranged as below.

First of all, the students in English major are selected randomly as subjects. What is more, they are given enough time to finish their tests individually. All the tests were handed in within 24 hours.
The test can be conducted effectively and smoothly. Therefore, the author can be able to get objective results and information, which is helpful for pragmatic failure research. The results and the discussion of the investigation are as below.

\section{RESULTS AND DISCUSSION}

Types of Pragmatic Failure in Cross-cultural Communication

The test is designed to serve the purpose of investigating the situation of pragmatic competence and the types of pragmatic failure of English students in University. The results of the pragmatical failure test are as followed.

Table-4.1: The test results of pragmalinguistic failures

\begin{tabular}{|c|c|c|c|}
\hline $\begin{array}{c}\text { Number of } \\
\text { Items }\end{array}$ & I & U & A \\
\hline 1 & 0 & 1 & 92 \\
\hline 2 & 0 & 1 & 92 \\
\hline 3 & 0 & 2 & 91 \\
\hline 4 & 0 & 4 & 89 \\
\hline 5 & 0 & 2 & 91 \\
\hline 6 & 2 & 3 & 88 \\
\hline 7 & 1 & 0 & 92 \\
\hline 8 & 0 & 2 & 91 \\
\hline 9 & 2 & 0 & 91 \\
\hline 10 & 0 & 1 & 92 \\
\hline 11 & 0 & 2 & 91 \\
\hline 12 & 1 & 3 & 89 \\
\hline 13 & 0 & 1 & 92 \\
\hline 14 & 0 & 3 & 89 \\
\hline 15 & 0 & 1 & 92 \\
\hline 16 & 0 & 2 & 91 \\
\hline 17 & 0 & 0 & 93 \\
\hline 18 & 0 & 0 & 93 \\
\hline 19 & 0 & 0 & 93 \\
\hline 20 & 0 & 0 & 93 \\
\hline
\end{tabular}


Table-4.2: The test results of sociolinguistic failures

\begin{tabular}{|c|l|l|l|}
\hline $\begin{array}{c}\text { Number of } \\
\text { Items }\end{array}$ & I & U & A \\
\hline 1 & 2 & 0 & 91 \\
\hline 2 & 3 & 0 & 90 \\
\hline 3 & 0 & 1 & 92 \\
\hline 4 & 3 & 0 & 90 \\
\hline 5 & 1 & 2 & 90 \\
\hline 6 & 0 & 2 & 91 \\
\hline 7 & 2 & 3 & 88 \\
\hline 8 & 0 & 2 & 91 \\
\hline 9 & 0 & 1 & 92 \\
\hline 10 & 0 & 0 & 93 \\
\hline 11 & 0 & 0 & 93 \\
\hline 12 & 0 & 0 & 93 \\
\hline 13 & 0 & 0 & 93 \\
\hline 14 & 0 & 0 & 93 \\
\hline 15 & 0 & 0 & 93 \\
\hline 16 & 0 & 0 & 93 \\
\hline 17 & 0 & 0 & 93 \\
\hline 18 & 0 & 0 & 93 \\
\hline 19 & 0 & 0 & 93 \\
\hline 20 & 0 & 0 & 93 \\
\hline & & & \\
\hline
\end{tabular}

As it is mentioned above, Thomas [4] divided pragmatic failure into two parts, which are pragmalinguistic failure and sociopragmatic failure. To investigate the concrete conditions of each type of pragmatic failure, the test has been designed to involve these two types of pragmatic failure. And from the result, it can be seen that the students of English major are more prone to commit in pragmatic failure in the cross-cultural communication.

For example, in Part One of the test, 20 statements are all designed to investigate the situation of students' pragmaliguistic competence. From 1 to 16, the statements are inappropriate, and from 17 to 20 are the appropriate statements. Under the result of the investigation, all the students choose " $\mathrm{A}$ " (appropriate) for the last 4 statements. However, 36 students choose the wrong answer in statement1-16. Some of them choose "A"(appropriate), the other choose "U"(uncertain), and the rest of them choose " I'(inappropriate) for the first 16 statements. According to the result of part one of the test, the average failure rate for the pragmalinguistic is $38 \%$.

In Part two of the test, 20 statements all designed to investigate the sociolinguistic competence of the students of English major. From 1-10, the statements are inappropriate, and from 11-20 are the appropriate statements. In the result of the investigation, all the students choose the correct answer " $\mathrm{A}$ " (appropriate) for the last ten statements. However, for the first ten statements, 24 students choose the wrong answer, some of them choose "A"(appropriate), and some of them choose "U" (inappropriate), and the rest of them choose the correct answer. Therefore, the average failure rate of sociolinguistic failure is $25 \%$.

The interview is conducted among 4 English teachers (T1, T2, T3, T4) who work in different grades with four questions to get their opinions on the pragmatic competence of the students of English major. Their opinions are presented below.

The first question: "How do you understand cross-cultural pragmatic failure?" All the teachers have their own understandings of the pragmatic failure in cross-cultural communication. T1 illustrates his understanding by presenting some examples to make a further explanation. T2 answers that cross-cultural pragmatic failure means inappropriate and ineffective communication between speakers from different countries when they are using the same language to communicate. While T3 and T4 didn't answer exact definitions of the question but present some examples to illuminate.

As for the second question: "What kinds of pragmatic failure are your students possible to commit?" The four teachers have different views. T2 and T3 state that pragmalinguistic failure is the part that students easily to make mistakes. While T1 and T4 answer that sociopragmatic failure is more common among students.

\section{Causes of Cross-cultural Pragmatic Failure}

As for the third question: What are the potential causes of the pragmatic failure in crosscultural communication? T1 replies that the main causes are the limitation of students' pragmalinguistic 
knowledge and social pragmatic competence. T2 says that the negligence of pragmalinguistic in teaching is also a primary cause. T3 and T4 have similar opinions upon this question. Therefore, the causes of crosscultural Pragmatic Failure can be divided into the following parts:

\section{Cultural Differences}

It is widely recognized by scholars that culture exerts a deep influence on language and cultural transfer usually occurs between two different cultures. According to Dai and Zhang [11], cultural transfer is caused by cultural differences. In the process of crosscultural communication, people often communicate according to their native cultural traditions and values. For example, Chinese people often choose to reject when others are praising them. They consider that accept the praise of others is a behavior of cockiness. However, in the eyes of American or British people, it is a strange phenomenon that confuses them a lot. Therefore, cultural difference is one of the main causes of cross-cultural failure. In the result of this investigation, it can be seen that the students of English major usually make mistakes during cross-cultural communication because of cultural differences. Some statements in part One of Test can be taken as examples:

Lisa says to you, "You look so beautiful on this dress!'You reply, "No. Not at all."

As for this statement, one third of the subjects choose $U$ (uncertain). One fifth of them chooses A (appropriate). In this statement, it is a typical expression in China, but it usually makes westerners confused and leaves them a misunderstanding that they didn't treat people well. In English speaking countries, people often say "thank you" to show their politeness when they are receiving praise.

Another statement: Lisa brings you a birthday gift wrapped in a box. You unwrap the box in front of her.

As for this statement, one in seventh of the subjects chooses $U$ (uncertain). They consider that it is not polite to unwrap the gift in private instead of unwrapping the gift in front of the guest. As for this statement, unwrapping the gifts received by guests is a kind of manner to show one's politeness in English speaking countries.

\section{The Pragmatic Competence}

According to Thomas [1], pragmatic competence is the ability to use language effectively in order to achieve a specific purpose and to understand the language in context. It can be seen in the investigation, the pragmatic competence still needs to improve since there are some students who made mistakes in the test. Taking the following statements as examples:

1. When you are having dinner with an English friend, you wish him or her, "Good appetite!"

One in fifth students chooses "U" (uncertain) upon this statement. The usage of "Good appetite" in Chinese means someone wishes the guest or friends enjoy themselves with dinner. However, it is improper for English expression habits. Therefore, it cannot achieve the purpose and to understand the language in context when people use "good appetite" to show their friendliness and hospitable.

2. You meet a new friend Peter at a party. When you say goodbye to him, he says, "We must get together soon." You can reply, "Thank you for your invitation! I expect it very much."

One in third students chooses "A" (appropriate) upon this statement. They haven't noticed the improper usage in this context; for English expression habits, the function of the usage of "We must get together soon" are similar with "See you" or "Goodbye," which has a great difference with the habits of expression in Chinese.

\section{Language Negative Transfer}

Language negative transfer is another cause of pragmatic failure. The pragmatic rules and cultural elements of students' mother language are supposed to influence their cultural values and thinking patterns, which may cause interference in learning and applying in English learning. Take some statements in the Test as examples:

1. You told your English speaking friends "I played tennis with David yesterday and I always won him."

In this statement, one-half students choose " $A$ " (appropriate). In Chinese, when people use the Chinese meaning of "won", it means someone has been beaten. However, in English expression habits, the proper word in this context should be "defeated".

2. On the street, you told your English speaking friends "grasp the time, or else we cannot catch the bus."

As for this statement, most students choose "I" (inappropriate), but a few students choose " $U$ " (uncertain). In this statement, the phrase "grasp the time" is inappropriate according to the English logic.

3.You say to your English speaking friends, "Excessive smoking will injure your body, so try to keep away from it." 
For this statement, one-half students choose "A" (appropriate). The word "body" in Chinese means not only physical body but also the condition of the whole body. However in English, it means the physical body only. In this context, the proper word should be "health" instead of "body".

\section{CONCLUSION \\ Major Findings}

To sum up, the significance of pragmatic competence in cross-cultural communication and based on the theories of pragmatic failure, this research of pragmatic failure in cross-cultural communication of English majors has been conducted objectively and smoothly through the test investigation and interview. With the help of the data, the research has achieved its goal. The situation of English majors' pragmatic failure still needs to improve.

- Pragmatic failures usually appear in pragmalinguistic and sociopragmatic aspects, which are $38 \%, 25 \%$ respectively.

- The teachers have a good knowledge of pragmatic failure and understand the current situation of pragmatic failure among students, which is benefit for improving students' pragmatic competence.

- The negative language transfer, the difference in culture, and values between China and western countries are the main causes result in English majors' pragmatic failure.

\section{Suggestions for Improving Students' Pragmatic Competence}

There are different cultures in different nations. Cultural differences often lead to cultural transfer, which refers to the situation where non- native speakers carry out cross-cultural communication according to the values of native culture. Being aware of the cultures of other countries is benefit for English learning and pragmatic competence improvement. Since pragmatic competence consists of pragmalinguistic competence and sociopragmatic competence, the suggestions are as bellowed.

\section{Develop Students' Pragmalinguistic Competence}

Kasper and Rose [5] reach a conclusion that not only prgmalinguistic but also sociopragmatic can be taught. One of the main difficulties in English learning for students is the shortage of English-speaking environment and language input. To develop students' pragmatic competence, teachers require integrating pragmatic knowledge in language teaching for pragmaliguistic teaching which can make students pay attention to the pragmatic knowledge in language using. First of all, improve teachers' pragmatic teaching level, innovate teachers' attitudes upon pragmatic knowledge, adjust teaching contents, teaching methods to meet the new requirement of pragmalinguistic competence cultivation. Second, teachers had better try to use the words "correct" and "incorrect" as less as possible, and try to use "proper" and "improper" when they are making the evaluation, which will help students understand the appropriate usage of language. Meanwhile, encourage students to explore the meaning and context of words, try to use authentic language materials as examples or exercise on the class, which may deepen students' understanding of the knowledge. In this way, grammar and pragmatic knowledge can both be improved. Third, the appropriate use of pragmatic knowledge of mother tongue would help a lot in English pragmatic knowledge teaching. In teaching process, it serves as a bridge which connects these two languages and become a benefit resource in learning pragmatic knowledge of target language. The appropriate use of mother tongue's pragmatic knowledge would improve students' sensitivity of pragmatic knowledge learning and reduce the appearance of negative language transfer.

\section{Develop students' Sociopragmatic Competence Arouse Students' Pragmatic Awareness}

Rose [15] claims that learners in the second language setting had stronger awareness of pragmatic than grammatical errors, whereas students in the foreign language setting were more aware of grammatical than pragmatic errors. Therefore, in the process of English learning, the learners' awareness should be aroused, which means teachers teaching should focus on knowledge application with the clear aim of cultivating students' pragmatic awareness.

\section{Cultivating Students' Cultural Sensitivity}

From the result of the investigation, it can be seen that cultural difference is one of the causes of the subjects' pragmatic failure. For English learners, cultural sensitivity often plays an important role in promoting their linguistic knowledge and pragmatic competence. As a result, cultivating students' cultural sensitivity is also an important solution for reducing the occurrence of pragmatic failure in cross-cultural communication.

\section{Renovating Teaching Ideologies and Methods}

Since teachers play an important role in students' language learning, it is necessary for teachers to do some change in helping to reduce the appearance of students. In today's language teaching, teachers have two things to face with: teaching ideologies and methods. For the former, teachers are required to have a better understanding of the relationship between language teaching and cultural impartation. The "student center" should not be forgotten in language teaching. As for teaching methods, teachers should renovate the methods they use with the development of the teaching ideologies.

\section{Enhancing Pragmatic Knowledge}

Pragmatic knowledge is the premise of pragmatic competence. During the language teaching procedures, pragmatic knowledge should be involved. In order to 
prevent or reduce the occurrence of pragmatic failure, pragmatic knowledge of students should be enhanced in the class or after class.

\section{Limitations and Further Suggestions}

Due to the limited academic experience of the author and the condition available, there are some limitations in the present research.

(1) The research is carried out in the form of the test. However, more research methods are needed to do the investigation of the current situation of the pragmatic failure of the students of English major. In addition, the interview method is also needed for further investigation among students.

(2) There are only 100 the students of English major from a Guangxi normal university in the investigation. They cannot represent all the students of English major, and the results of the research may differ from the number of subjects. So, the credibility would be much higher if the investigation involves a larger scale.

(3) There are only 3 suggestions for English teaching in order to prevent or reduce the appearance of pragmatic failure. Actually, more suggestions are needed to improve teaching quality.

It is clear that pragmatic competence is of great importance, and more studies of pragmatic competence and pragmatic failure should be made. The limitation of this investigation provides some suggestions for future research on related issues.

First of all, in order to ensure the reliability of the test, more questions that are related to cross-cultural communication and can be reflect the pragmatic failure of the students of English major should be included. What is more, the test has some restricted shortcomings. The subjects are careful and thoughtful than usual when they are answering the questions in the test. So the better way to collect a more reliable method is to record the situation when the subjects are having a cross-cultural communication with English speaking foreigners. However, this is a more accurate but complicated way and it needs more time and energy to finish. Second, more subjects should be included in the investigation. The credibility would be improved greatly if the research done on a much larger scale. Additionally, students with different grades, different gender, and different age should be involved in order to get a much more comprehensive understanding of the different pragmatic failures of different subjects.

\section{REFERENCE}

1. Thomas, J. (1983). Cross-cultural Pragmatic Failure. Applied Linguistics, 20(2) 91-112.

2. Harms, L.S. (1973). Intercultural Communication. New York: Harper \& Row.
3. Wang, Q. (2000). Course of English Teaching Method. Higher Education Press.

4. Thomas, J. (1995). Meaning in Interaction: an Introduction to Pragmatics. London: Longman Group Limited.

5. Kasper, G. (2002). Pragmatic Development in a Second Language. Language Learning, 40(1); 212352.

6. Huang, C. D. (1984). Pragmatics and Pragmatic Errors. Foreign Languages, 7(1), 13-18.

7. He, Z. R. \& Yan, Z. (1986). Pragmatic Failures of Chinese Students in English Communication-A Survey of Chinese-English Differences. Foreign Language Teaching and Research, 17(3); 52-57.

8. Wang, D. X. (1990). Pragmatic Issues in Intercultural Communication. Foreign Language Teaching and Research, 44 (4); 52-58.

9. Jia, Y. X. (1997). Intercultural Communication. Shanghai Foreign Language Education Press.

10. Ge, L. L. (2002). Pragmatics of Teaching. Hunan: National University of Defense Technology Press.

11. Dai, W. D., \& Zhang, H. L. (2002). Enlightenment of Cultural Transfer in Foreign Language Communication on Foreign Language Teaching and Reform. Foreign Languages, 3(2)' 2-8.

12. Lu, W. H. \& Lu, J. K. (1993). Pragmatic Failures of Foreigners in Learning Chinese. Chinese Language Learning, 5(1). 41- 44.

13. Han, D. H., \& Yao, W. Q. (2002). Investigation and Analysis of Pragmatic Competence of Foreign Majors. Journal of Xi'an International Studies University, 4(4), 79-82.

14. Zhu, J., \& Zhou, H.R. (2015). Pragmatic Competence Training for College English Majors. Overseas English, 15(1),133-134.

15. Rose, A. J., \& Rudolph, K. D. (2006). A review of sex differences in peer relationship processes: potential trade-offs for the emotional and behavioral development of girls and boys. Psychological bulletin, 132(1), 98.

\section{Appendixes \\ Test \\ (Adapted from socio-cultural test by Wang (1990)) Instructions}

This test is only employed for the academic research and will be kept confidential. Please answer all the questions honestly. Notice that all the English names presented here are referred to native English speakers.

\section{Part One}

Directions: There are 20 statements in this section. Each statement has an italic part which describes a verbal behavior in cross-cultural interaction. Read each statement and decide whether the italic part is appropriate or inappropriate. If it is appropriate, write "A"; if inappropriate, write "I". If you are uncertain, write " $U$ " on the answer sheet. Mark your answer on the list of "Your choice". 


\begin{tabular}{|c|c|c|}
\hline \multicolumn{3}{|c|}{$\mathrm{A}=$ Appropriate $\mathrm{I}=$ Inappropriate $\mathrm{U}=$ Uncertain } \\
\hline Items & Statements & Your choice \\
\hline 1 & $\begin{array}{l}\text { David asks Xiaoming, "what does your grandfather do?" Xiaoming answers, "He sees the } \\
\text { gate for a factory." }\end{array}$ & \\
\hline 2 & $\begin{array}{l}\text { Lily looks at the girls on the beach and say to her friend, "Look at them, they are shining the } \\
\text { sun!" }\end{array}$ & \\
\hline 3 & $\begin{array}{l}\text { When Lihua introduces his teacher, he says, "Mr. Lin is a great teacher. Peaches and plums } \\
\text { all over the world." }\end{array}$ & \\
\hline 4 & Lisa says to you, "You look so beautiful on this dress!" You reply, “No. Not at all." & \\
\hline 5 & $\begin{array}{l}\text { You are impressed by the beautiful picture drew by Lisa. You can say, "I didn't expect you } \\
\text { could draw such pretty picture." }\end{array}$ & \\
\hline 6 & $\begin{array}{l}\text { You told your English speaking friends "I played tennis with David yesterday and I always } \\
\text { won him." }\end{array}$ & \\
\hline 7 & $\begin{array}{l}\text { On the street, you told your English speaking friends "grasp the time, or else we cannot } \\
\text { catch the bus." }\end{array}$ & \\
\hline 8 & In London, you tell the drive, "airport, please!" & \\
\hline 9 & Professor Jones invites you to have dinner. You can say, "Thank you, I will try to come." & \\
\hline 10 & $\begin{array}{l}\text { You invite David to enjoy green tea. After he has a drink, you can offer, "please have } \\
\text { another drink!"” }\end{array}$ & \\
\hline 11 & $\begin{array}{l}\text { If you want your colleague David to pass you the newspaper, you can say to him, "You } \\
\text { would be doing me a great favor if you could pass me the newspaper." }\end{array}$ & \\
\hline 12 & When you are having dinner with an English friend, you wish him or her, "Good appetite!" & \\
\hline 13 & $\begin{array}{l}\text { You meet a new friend Peter at a party. When you say goodbye to him, he says, "We must } \\
\text { get together soon." You can reply, "Thank you for your invitation! I expect it very much." }\end{array}$ & \\
\hline 14 & $\begin{array}{l}\text { Lisa leaves your house and says to you, "Goodbye." You can reply, "Walk slowly. Do come } \\
\text { again." }\end{array}$ & \\
\hline 15 & $\begin{array}{l}\text { On a cold winter day, you meet Professor Jones. You can say to him, "it is rather cold. } \\
\text { You'd better wear more clothes, keep warm and not catch cold." }\end{array}$ & \\
\hline 16 & $\begin{array}{l}\text { You say to your English speaking friends, "Excessive smoking will injure your body, so try } \\
\text { to keep away from it." }\end{array}$ & \\
\hline 17 & $\begin{array}{l}\text { As a hotel receptionist, you can say to an English speaking tourist, "For registration purpose } \\
\text { I need some information. Would you mind telling me your age?" }\end{array}$ & \\
\hline 18 & $\begin{array}{l}\text { You have something to tell Mr. Brown, head of the department, so you can say to him, "Can } \\
\text { I have a word with you? Mr. Brown?" }\end{array}$ & \\
\hline 19 & $\begin{array}{l}\text { David asks if you mind his smoking. If you don't like the smell, you can say, "Would you } \\
\text { mind if I say no?" }\end{array}$ & \\
\hline 20 & $\begin{array}{l}\text { You work as a secretary in an American company. One day you work very late. Your boss } \\
\text { says to you, "Thanks. That is a great help." You can reply, "It is my pleasure." }\end{array}$ & \\
\hline
\end{tabular}

\section{Part Two:}

Directions: There are 20 statements in this section. Each statement has an italic part which described a non-verbal behavior in cross-cultural interaction. Read each statement and decide whether the italic part is appropriate or inappropriate. If it is appropriate, write "A"; if inappropriate, write "I". If you're uncertain, write "U" on the answer sheet. Mark your answer on the list of "Your choice".

\begin{tabular}{|l|l|l|}
\hline \multicolumn{1}{|c|}{ A= Appropriate I= Inappropriate U= Uncertain } & $\begin{array}{l}\text { Your } \\
\text { Items }\end{array}$ \\
\hline 1 & Statements & \multicolumn{1}{|c|}{ You use one of your hands to receive a gift gave from Lisa. } \\
\hline 2 & If you are invited to dinner by your English speaking friends, you can bring yellow flowers as a gift. & \\
\hline 3 & In English speaking countries, you can pat a kid on the forehead to show your friendliness. & $\begin{array}{l}\text { Studying in America, you should keep silence and not argue with your teacher during the class to } \\
\text { show your respect. }\end{array}$ \\
\hline 4 & $\begin{array}{l}\text { During the break in an academic meeting, you can go over and talk to the American professor as long } \\
\text { as the break permits. }\end{array}$ & $\begin{array}{l}\text { Studying in America, if you feel ill and cannot attend the class, you can just send the teacher an e- } \\
\text { mail and don't have to give details about your illness. }\end{array}$ \\
\hline 5 & $\begin{array}{l}\text { When you visit your English friend on a rainy day, you complain about the weather and say that you } \\
\text { hate rainy day. }\end{array}$ & \\
\hline 7 &
\end{tabular}




\begin{tabular}{|l|l|l|}
\hline 8 & $\begin{array}{l}\text { To express your gratitude to your American teacher David, you can give him a piece of hand-made } \\
\text { works. }\end{array}$ & \\
\hline 9 & If you are invited to dinner by your Canadian friend David, you expected him to offer you a cigarette. & \\
\hline 10 & You can buy many drugs without a doctor's prescription in English speaking countries. & \\
\hline 11 & When you are talking to an English speaking friend, you should keep eye contact with him or her. & \\
\hline 12 & $\begin{array}{l}\text { When you talk with the strangers from English speaking countries, you'd better keep a distance about } \\
1 \text { to } 3 \text { meters. }\end{array}$ & \\
\hline 13 & Lisa brings you a birthday gift wrapped in a box. You can unwrap the box in front of her. & \\
\hline 14 & At a dinner you can begin to eat when the hostess picks up her own spoon or fork. & \\
\hline 15 & $\begin{array}{l}\text { If you are going to take part in a banquet held by your English speaking friend, you can wear some } \\
\text { perfume to show your respect to others. }\end{array}$ & \\
\hline 16 & In English speaking countries you usually first introduce a man to a women. & \\
\hline 17 & If you are a male and introduced to an English speaking lady, you should hold out your hand first. & \\
\hline 18 & $\begin{array}{l}\text { In English speaking countries, it is more polite to type the letter of invitation for the party instead of } \\
\text { writing them with a pen. }\end{array}$ & \\
\hline 19 & In English speaking countries, you should tip the waiter or the waitress who serves you. & \\
\hline 20 & $\begin{array}{l}\text { When you have a toothache and want to see a dentist, you should make an appointment before you } \\
\text { go. }\end{array}$ & \\
\hline
\end{tabular}

